\title{
A informação no contexto organizacional: tipos, características e usos
}

The information in the organizational context: types, characteristics and uses

\author{
Cássia Regina Bassan de Moraes (1) e Bárbara FADEL (2)
}

(1) Faculdade de Tecnologia, Fatec Garça. Av. Presidente Vargas, 2331, Garça, São Paulo, Brasil, CEP 17.400-000, cassiabassan@flash.tv.br (2) Faculdade de Filosofia e Ciências, Unesp, Av. Hygino Muzzi Filho, 737, Marília, São Paulo, Brasil CEP: 17525-900 e Centro Universitário de Franca, Uni-FACEF, Av. Major Nicácio, 2433, Franca, São Paulo, Brasil, CEP 14.401-135, bafadel@terra.com.br

\section{Resumen}

Cada vez más la información se consolida como elemento crucial para el desempeño de las organizaciones, como apoyo a las decisiones, como factor de producción y ejerciendo influencia sobre el comportamiento de las personas. Así que el objetivo de este estudio ha sido caracterizar el tipo de información que es de interés para las organizaciones. Como metodología, se realizó una revisión de la literatura, haciendo una encuesta sobre la cuestión de la información en las organizaciones. Como resultado, se obtuvo un cuadro que caracteriza estas informaciones de naturaleza variada. Se concluye que, muchas veces, la información necesaria para la toma de decisiones en las organizaciones es considerada confidencial o presenta un alto coste de acceso, en función de su valor económico.
\end{abstract}

Palabras clave: Información organizacional. Información. Tipología. Características. Usos. Ambientes informacionales. Organizaciones.

\section{Introdução}

A informação cada vez mais se consolida como elemento crucial para o desempenho das organizações, uma vez que serve de apoio às decisões, como fator de produção, exerce influências sobre o comportamento das pessoas e passa a ser um vetor importantíssimo, pois pode multiplicar a sinergia dos esforços ou anular o resultado do conjunto destes.

Para a definição de informação, há que se considerar o trinômio dado, informação e conhecimento, ao considerar-se que aquela serve de conexão entre o dado bruto e o conhecimento.

Desta forma, costuma-se definir dados como as observações sobre o estado do mundo; informação, como os dados com relevância e propósito, propriedades atribuídas aos dados pelos seres humanos; e conhecimento, como a informação a qual foi dado um contexto, um significado, uma interpretação, ou seja, alguém refletiu sobre o conhecimento, acrescentou a ele sua

\begin{abstract}
Information is more and more considered a crucial element determining organizational performance, or supporting decisions, as a production factor, and exercing influence on people's behavior. Therefore, the objective of this paper has been to characterize the types of information that are of the interest of organizations. For this, a literature review and a survey was carried out. As results, it was obtained a board of characteristics of information in organizations. It was also concluded that frequently the necessary information to take decisions is confidential, or presents high access costs, due to their economic value.
\end{abstract}

Keywords: Information. Organizations. Information types. Information characteristics. Information uses. Informational environment.

própria sabedoria, considerou suas implicações mais amplas.

O objetivo deste estudo foi o de caracterizar o tipo de informação que é de interesse para as organizações, uma vez que tais informações são aquelas que possuem valor comercial e que possibilitam maximizar os processos de produção ou viabilizar seu desenvolvimento. Para tanto, como metodologia, lançou-se mão de uma revisão de literatura, fazendo-se um levantamento sobre a questão da informação nas organizações entre autores contemporâneos.

\section{O valor da informação}

Historicamente, a informação vem sofrendo uma evolução, provocando alterações não apenas nos indivíduos, mas também nas sociedades e nas organizações. Segundo Calazans (2006, p. 63), a humanidade está vivenciando a quarta revolução da informação na história. 
Segundo a autora, a primeira revolução foi a invenção da escrita (há aproximadamente 6 mil anos) e a segunda foi a do livro escrito (China em 1300 a.C.); sobre estas duas revoluções há poucas evidências do impacto social efetuado. A terceira revolução da informação foi causada pela invenção da imprensa e do tipo móvel por Gutenberg (entre 1450 e 1455) e, diferentemente das outras, é possível identificar os seus impactos. Em pouco tempo a revolução da imprensa mudou instituições e o sistema de ensino, definindo o ensino universal, ou seja, a escola de hoje, bem como tornou possível várias outras modificações na sociedade, ensino e cultura (Drucker, 1999).

Calazans (2006, p. 63) ainda acrescenta que a quarta revolução da informação, que está em andamento, vem ocorrendo nos últimos 50 anos. Baseada na imprensa, caracteriza-se pelo crescimento exponencial de livros e revistas, nos variados campos e interesses. Sua finalidade dessas publicações não é o entretenimento nem a educação, mas a informação (Drucker, 1999). A possibilidade da utilização dos canais eletrônicos, neste contexto, tende a aprofundar, ainda mais, as mudanças do significado da informação tanto para os indivíduos como para as organizações.

Para Dias e Belluzzo (2003, p. 35) as organizações necessitam de informações além daquelas tradicionalmente fornecidas pelos sistemas de bibliotecas com fins educativos, de erudição ou de lazer. Tais informações são aquelas que possuem valor comercial e que possibilitam maximizar os processos de produção ou viabilizar seu desenvolvimento. Essas informações de natureza variada podem ser caracterizadas em diferentes tipos: cientifica, tecnológica, estratégica e de negócios. O quadro 1 a seguir detalha as características de cada uma delas.

Embora existam classificações distintas para os diferentes tipos de informação, há uma superposição entre a sua natureza e função, uma complementando a outra, ou ainda, uma como conseqüência da outra. Muitas vezes, as informações necessárias à tomada de decisão pelas organizações são consideradas sigilosas ou se apresentam com alto custo para acesso, em função do seu valor econômico podendo estar implícita no conhecimento tácito (1) (Dias; Belluzzo, 2003).

Tanto a informação científica, tecnológica, estratégica como aquelas para negócios, inclui ainda, outros tipos tais como: comercial, econômicofinanceira, regulamentar e jurídica, ambiental e de segurança, formando a base de conhecimento utilizada para tomada de decisão nas organizações (Battaglia, 1999).

\begin{tabular}{|c|c|}
\hline Tipo de informação & Características \\
\hline Científica & $\begin{array}{l}\text { A informação cientifica é o } \\
\text { conhecimento resultante da } \\
\text { pesquisa que se acrescenta ao } \\
\text { entendimento universal existente. }\end{array}$ \\
\hline Tecnológica & $\begin{array}{l}\text { A informação tecnológica é todo } \\
\text { tipo de conhecimento relacionado } \\
\text { com o modo de fazer um produto } \\
\text { ou prestar um serviço, tendo como } \\
\text { objetivo a sua colocação no } \\
\text { mercado. }\end{array}$ \\
\hline Estratégica & $\begin{array}{l}\text { A informação estratégica é a que } \\
\text { se refere ao conhecimento das } \\
\text { tendências do mercado, das } \\
\text { conjunturas econômicas que } \\
\text { afetam o comportamento do } \\
\text { mercado, das empresas } \\
\text { fornecedoras de insumos, } \\
\text { matérias-primas e produtos } \\
\text { concorrentes das organizações } \\
\text { concorrentes, e implantação ou em } \\
\text { expansão e do seu ambiente } \\
\text { operacional. }\end{array}$ \\
\hline Negócios & $\begin{array}{l}\text { A informação de negócios é aquela } \\
\text { que subsidia o processo decisório } \\
\text { do gerenciamento das empresas } \\
\text { industriais, de prestação de } \\
\text { serviços e comerciais, nos } \\
\text { seguintes aspectos: companhias, } \\
\text { produtos, finanças, estatísticas, } \\
\text { legislação e mercado. }\end{array}$ \\
\hline
\end{tabular}

Quadro 1. Tipos de Informação (Adaptado de Dias, Beluzzo, 2003).

Por sua vez os diferentes tipos de informações apresentam dimensões diversas dependendo da forma de veiculação e conforme o conteúdo e meios utilizados. Adquirem formatos específicos para facilitar sua divulgação e utilização, em função dos diferentes veículos de comunicação existentes.

A informação para tomada de decisão e a garantia da qualidade dos produtos e serviços oferecidos pelas organizações envolve a busca dirigida para objetivos diferenciados. Dentre eles, destacam-se: questões de pesquisas relacionadas à melhoria contínua de processos e atividades, bem como quanto à inovação e avaliação de tecnologias para formação de competências em mercados concorridos.

Por fim, as fontes à disposição das organizações apresentam-se em diversos suportes, do meio impresso ao digitalizado. Com o avanço das tecnologias de informação tem ocorrido um esforço enorme no sentido de aumentar a oferta de fontes em meio eletrônico. 


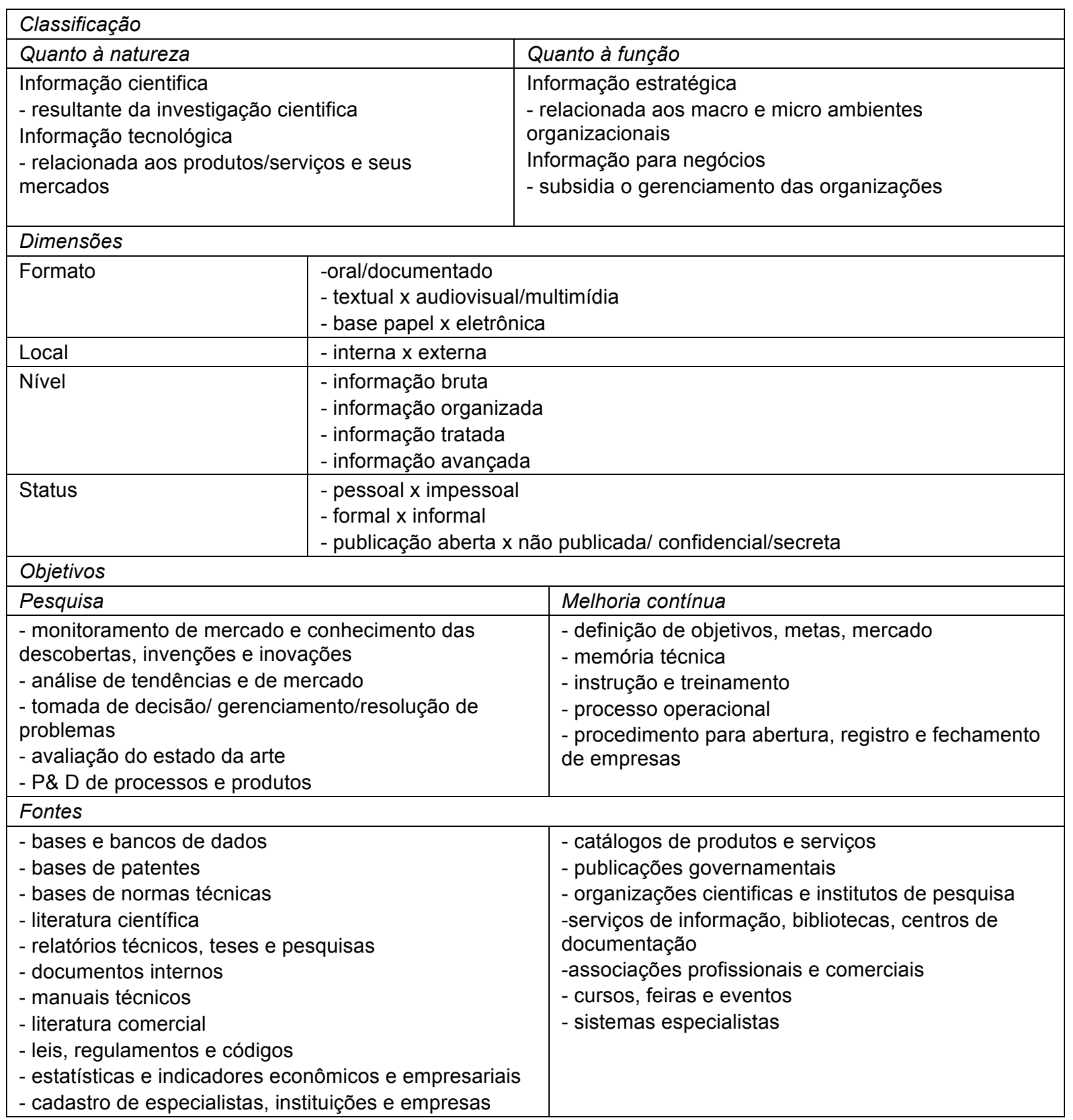

Quadro 2. A Informação nas organizações (Dias, Beluzzo, 2003).

Segundo Drucker (1999), desde o surgimento das novas ferramentas de processamentos os homens de negócios tanto têm exagerado, como também subestimado a importância das informações na organização. Chegou-se ao exagero de se aventar a possibilidade de se gerar "modelos de negócios" por computador, que poderiam tomar decisões e até mesmo dirigir grande parte da empresa. Por outro lado, as novas ferramentas foram vistas apenas como o meio para se fazer melhor aquilo que os executivos já estavam fazendo para administrar suas organizações.
Por outro lado, conceitos e ferramentas são mutuamente interdependentes e interativos, um causando a mudança do outro. Isso acontece agora com o que é denominado de organização, e com as ferramentas denominadas de informação. Estas capacitam e impulsionam a ver as organizações de forma diferente, havendo uma marcante agregação de valor às informações, por permitir reprojetar o que os administradores terão de gerir (Drucker, 1999).

Para Stair (1998, p. 05), a transformação de dados em informação é um processo, ou uma série de tarefas logicamente relacionadas, executadas para atingir um resultado definitivo. $\mathrm{O}$ 
processo de definição de relações entre dados requer conhecimento. Conhecimento é o corpo ou regras, diretrizes e procedimentos usados para selecionar, organizar e manipular os dados, para torná-los úteis para uma tarefa espe- cífica. Ainda segundo Stair (1998), a informação para ser valiosa para os gestores tem que ter as seguintes características:

\begin{tabular}{|c|c|}
\hline Características & Definições \\
\hline Precisa & $\begin{array}{l}\text { A informação precisa não pode ter erros. Em alguns casos, a informação imprecisa é gerada } \\
\text { pela entrada de dados incorretos no processo de transformação. Isto é comumente chamado } \\
\text { de entrada lixo, sai lixo (ESL). }\end{array}$ \\
\hline Completa & $\begin{array}{l}\text { A informação completa contém todos os fatos importantes. Por exemplo, um relatório de } \\
\text { investimento que não inclui todos os custos importantes não está completo. }\end{array}$ \\
\hline Econômica & $\begin{array}{l}\text { A informação também deve ser de produção relativamente econômica. Os tomadores de } \\
\text { decisões devem sempre fazer um balanço do valor da informação com custo da sua produção. }\end{array}$ \\
\hline Flexível & $\begin{array}{l}\text { A informação flexível pode ser usada para diversas finalidades. Por exemplo, a informação de } \\
\text { quanto se tem de estoque disponível de uma determinada peça pode ser usada pelos } \\
\text { representantes de vendas no fechamento de uma venda, por um gerente de produção para } \\
\text { determinar o valor total que a empresa tem investido em estoques. }\end{array}$ \\
\hline Confiável & $\begin{array}{l}\text { A informação confiável pode ser dependente. Em muitos casos, a confiabilidade da informação } \\
\text { depende da confiabilidade do método de coleta de dados. Quer dizer, a confiabilidade depende } \\
\text { da fonte de informação. Um boato vindo de fonte desconhecida que os preços do petróleo } \\
\text { devem subir pode não ser confiável. }\end{array}$ \\
\hline Relevante & $\begin{array}{l}\text { A informação relevante é importante para a tomada de decisões. A informação de que os } \\
\text { preços da madeira de construção devem cair pode não ser relevante para um fabricante de } \\
\text { chips de computador. }\end{array}$ \\
\hline Simples & $\begin{array}{l}\text { A informação também pode ser simples, não deve ser exageradamente complexa. A } \\
\text { informação sofisticada e detalhada pode não ser necessária. Na realidade, informação em } \\
\text { excesso pode causar sobrecarga de informação, quando um tomador de decisões tem } \\
\text { informação demais e não consegue determinar o que é realmente importante. }\end{array}$ \\
\hline Em tempo & $\begin{array}{l}\text { A informação em tempo é enviada quando necessário. Saber as condições do tempo da } \\
\text { semana passada não ajudará a decidir qual agasalho vestir hoje. }\end{array}$ \\
\hline Verificável & $\begin{array}{l}\text { Finalmente, a informação deve ser verificável. Isto significa que se pode checá-la para saber se } \\
\text { está correta, talvez checando várias fontes da mesma informação. }\end{array}$ \\
\hline
\end{tabular}

Quadro 3. As características da boa informação (Stair, 1998, p. 6).

Para que as organizações ajustem-se rapidamente às mudanças, é preciso dispor de informações de qualidade, oportunas e confiáveis para que possam dar suporte adequado às decisões. Desta forma, o valor da informação pode ser medido pela maneira como ela ajuda os tomadores de decisões a atingirem os objetivos e metas da organização.

Assim, deve-se estar atento à organização dos recursos da informação, identificando-se não só as necessidades de informações, mas, inclusive, a tecnologia disponível para gerenciá-las.

Nesse sentido, a tecnologia de informação, destaca-se como um recurso cada vez mais fundamental de competitividade empresarial, oferecendo um amplo leque de oportunidades, especialmente, quando aliadas às tecnologias de comunicações.

Diante desse quadro, são fundamentalmente as características da organização que irão deter- minar as formas e os meios a serem adotados na análise das informações e no desenvolvimento de sistemas de informação, partindo do princípio que existe uma interdependência entre informação e organização. Mas, apesar da importância e necessidade da informação, persistem alguns desafios para que os sistemas de informação sejam a mola propulsora das organizações, tais como:

- Consolidar métodos e tecnologias para uma maior automação e integração da informação, que permitam às empresas criar um fluxo ágil e consistente;

- Aperfeiçoar os métodos e técnicas para o gerenciamento da informação;

- Definir claramente as demandas dos novos sistemas;

- Avaliar e levar em consideração os impactos dos Sistemas de Informações para a estrutura 
formal e informal da organização (e viceversa).

\section{Considerações finais}

Como resultados, obteve-se um quadro que caracteriza estas informações de natureza variada, e que podem ser caracterizadas em diferentes tipos: científica, tecnológica, estratégica e de negócios.

Conclui-se, também, que, muitas vezes, as informações necessárias à tomada de decisão pelas organizações são consideradas confidenciais ou apresentam-se com alto custo de aceso, em função de seu valor econômico. Tanto a informação científica, tecnológica, estratégica e de negócios, pode incluir, ainda, outros tipos tais como: comercial, econômico-financeira, regulamentar e jurídica, ambiental e de segurança, formando a base de conhecimento usada para a tomada de decisões nas organizações.

O propósito deste artigo foi apresentar a informação além das bibliotecas, num contexto organizacional, na qual ela tem um valor comercial para enfrentar os mercados competitivos. Essa procura constante de melhorias contínuas tem levado a administrar a informação na organização com uma percepção que as práticas adotadas são fundamentais em transformar dados em informação e conhecimento, a fim de se melhorar o desempenho.

Há que se levar em conta as habilidades da liderança das organizações para adaptar a cultura organizacional nesse processo de transformação de informação em conhecimento.

\section{Notas}

(1) Para Nonaka e Takeuchi (1997), há dois tipos de conhecimento: o tácito, referente à experiência, ao poder de inovação e à habilidade dos empregados de uma companhia para realizar as tarefas do dia-a-dia, e o explícito, ligado aos procedimentos, aos bancos de dados, às patentes e aos relacionamentos com os clientes.

\section{Referências}

Battaglia, M. da G. B. A inteligência competitiva modelando o sistema de informação de clientes - Finep. // Ciência da Informação. 28:21 (maio/ago. 1999) 200-214.

Calazans, A.T.S. (2006). Conceitos e uso da informação organizacional e informação estratégica. // TransInformação. 18: 1 (jan./abr., 2006) 63-70.

Drucker, P. (1999). Desafios gerenciais para o século XXI. São Paulo: Pioneira, 1999

Dias, M. M. K.; Beluzzo, R. C. B. (2003). Gestão da informação em ciência e tecnologia sob a ótica do cliente. Bauru: Edusc, 2003.

Nonaka, I.; Takeuchi, H. (1997). Criação de conhecimento na empresa: como as empresas japonesas geram a dinâmica da inovação. Rio de Janeiro: Editora Campus, 1997.

Stair, M.R. (1998). Princípios de sistemas de informação. Rio de Janeiro: LTC, 1998. 